\title{
SECOND-ORDER ANALYSIS OF STEEL SHEET PILES BY PILE ELEMENT CONSIDERING NONLINEAR SOIL-STRUCTURE INTERACTIONS
}

\author{
Wei-Hang Ouyang ${ }^{1}$, Yi Yang ${ }^{2, *}$, Jian-Hong Wan ${ }^{1}$ and Si-Wei Liu ${ }^{3}$ \\ ${ }^{1}$ School of Civil Engineering, Sun Yat-Sen University, Zhuhai, P.R. China \\ ${ }^{2}$ Department of Civil Engineering, Chu Hai College of Higher Education, Hong Kong, China \\ ${ }^{3}$ Department of Civil and Environmental Engineering, The Hong Kong Polytechnic University, Hong Kong, China \\ * (Corresponding author: E-mail: yyang@chuhai.edu.hk)
}

\section{A B S T RA C T}

Comparing to other supporting pile walls, steel sheet piles with a lower flexural rigidity have a more obvious and significant second-order effect with the large deformation. Also, the nonlinear Soil-Structure Interaction (SSI) can highly influence the efficiency and accuracy of the deformation and buckling of the steel sheet pile. Currently, some empirical methods with linear assumptions and the discrete spring element method are always used for the design of steel sheet piles in practical engineering. However, these methods are normally inaccurate or inefficient in considering the nonlinear SSI and the second-order effect. In this paper, a new line element, named pile element, is applied to analyze the structural behaviors of the steel sheet pile. In this new element, the soil resistance and pressure surrounding the pile as well as the pile shaft resistance are all integrated into the element formulation to simulate the nonlinear SSI. The Gauss-Legendre method is innovatively introduced to elaborate the realistic soil pressure distribution. For reducing the nonlinear iterations and numerical errors from the buckling behavior, the proposed numerical method and Updated-Lagrangian method will be integrated within a Newton-Raphson typed approach. Finally, several examples are given for validating the accuracy and efficiency of the developed pile element with the consideration of the realistic soil pressures. It can be found that the developed pile element has a significant advantage in simulating steel sheet piles.
ART I CLE HISTORY

$\begin{array}{ll}\text { Received: } & 27 \text { October } 2020 \\ \text { Revised: } & 11 \text { November } 2020 \\ \text { Accepted: } & 12 \text { November } 2020\end{array}$

\section{K E Y W O R D S}

Steel sheet pile;

Finite element method;

Soil-structure interactions;

Lateral earth pressure;

Pile deflection;

Second-order effect

\section{Copyright $@ 2020$ by The Hong Kong Institute of Steel Construction. All rights reserved.}

\section{Introduction}

Steel sheet piles are widely used to support the excavation in urban areas. Many single sheet piles through interlocks to generate steel sheet pile wall as shown in Fig.1 (a). Normally, the installation method for the steel sheet pile is vibratory driving, which is a straightforward technique and usually used in the supporting projects $[1,2]$. Comparing with the installation of the steel sheet pile, however, its design is much more difficult.

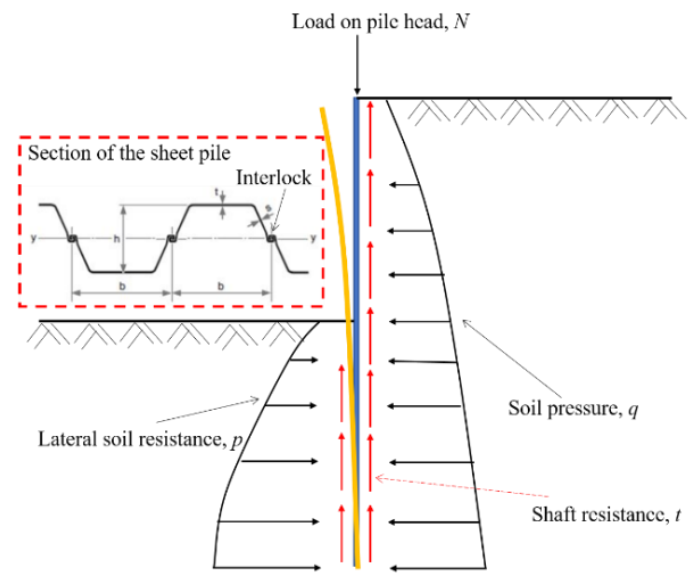

(a) Schematic of the steel sheet pile

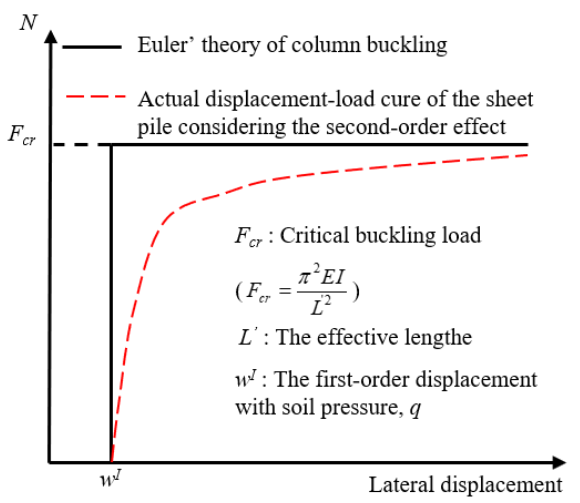

(b) Displacement-load curve of the steel sheet pile

Fig. 1 Design framework of the steel sheet pile

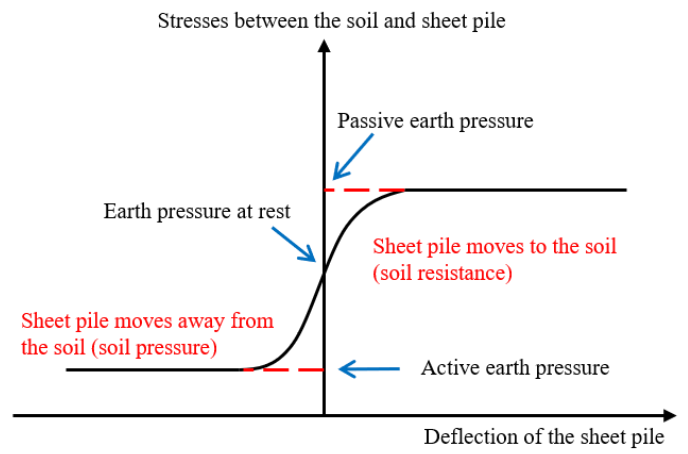

(a) The relationship between the earth pressure and the lateral deflection of the sheet pile

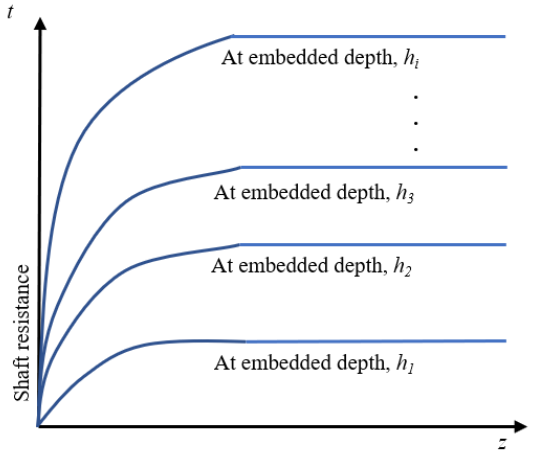

(b) The relationship between the shaft resistance and the vertical deflection of the sheet pile

Fig. 2 The Soil-Structure Interaction (SSI) relationships of the sheet pile

Steel sheet pile can be easily transported and installed. However, its bearing capacity is lower than other supporting types. As a flexible supporting structure, the ultimate capacity of the steel sheet pile cross-section and maximum deformation should be carefully considered in the design procedure [3]. Also, its second-order effect is significant because of the large deformation.(Fig.1 (b)) $[4,5]$. Thus, how to accurately describe the buckling behavior of steel sheet piles is really important.[6]. Comparing to the complicity of the structural behavior, the highly nonlinear Soil-Structure Interaction (SSI) [7-9] in steel sheet pile is also essential for the steel pile deformation and much more complicated. As the lateral pressure and resistance (as shown in Fig.2 (a)) can highly influence the structural behaviors of steel sheet piles $[10,11]$, 


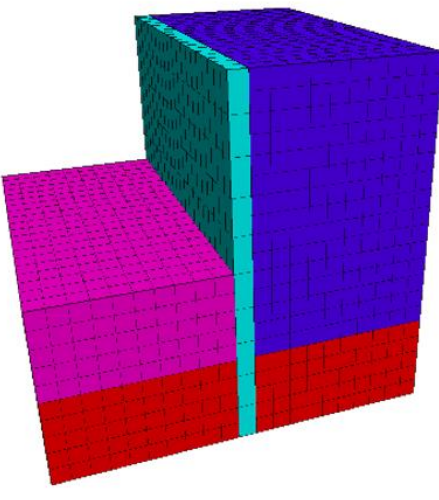

(a) Three-dimension solid

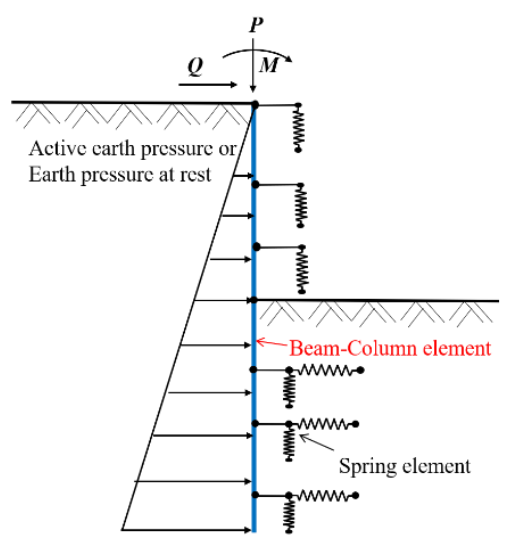

(b) Discrete spring element

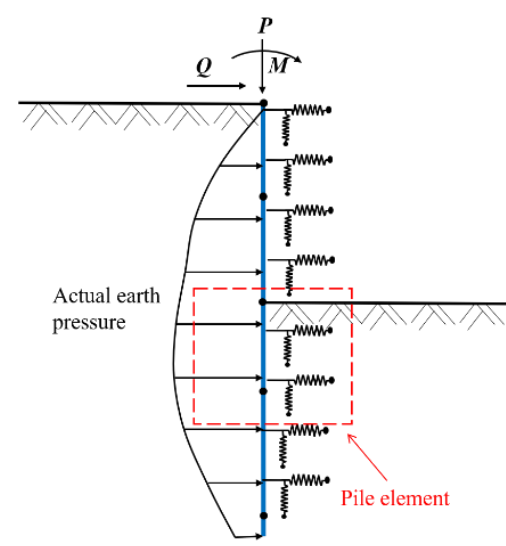

(c) Pile element

Fig. 3 Different finite element models for the sheet pile

different researches have been carried out [12-17]. Rankine and Coulomb theories are two most common theories in the study of retaining walls [12]. Many researchers have developed these two classical theories to consider other factors [13, 14]. Although these lateral earth-pressure theories have clear physical meanings and are easy to be applied, their shortcomings are obvious, where soil pressure, especially the passive pressure in front of the steel sheet pile, is only mobilized on a large displacement. In practical projects, the allowed displacement is normally smaller than the limit deformation in classical theories, where the lateral pressure distribution is nonlinear $[15,16]$. For this reason, Duncan et al. [17] introduced the initial soil stiffness and other parameters into the hyperbolic relationship and built the relationship between the soil resistances in front of the pile $(p)$ and the lateral pile deflection $(y)$ for considering the resistance-deflection behavior. Additionally, the SSI also includes the relationship between pile shaft resistance $(t)$ and its vertical displacement $(z)$ [18](as shown in Fig.2 (b)), which should also be properly measured into the design of the steel sheet pile, especially considering its second-order effect.

For accurately describing the SSI and second-order effect, finite difference and finite element method are usually considered. In the finite difference method, the nonlinear SSI cannot be accurately captured [19]. Hence, the finite element with the capacity of simulating an accurate and nonlinear SSI is usually selected for solving steel sheet pile problems. In the finite element method, there are two main approaches: one is used three-dimension solid element [20] (Fig. 3 (a)); the other one is used the discrete spring element [21] (Fig. 3 (b)). The three-dimension solid element method can be directly used to build a realistic model of steel sheet pile wall and surrounding soils, where the realistic SSI can be considered. However, the modeling procedure is rather complicated and time-consuming. These factors restrain the three-dimension solid element method mainly in the research area. Thus, the most common finite element model used in practical engineering is the discrete spring element method based on the Winkler foundation beam method. In the discrete spring element method, the complicated structural behaviors of the sheet pile wall can be described by a large number of elements which will decline the efficiency of design. Another shortcoming is that the lateral pressure behind the steel sheet pile is assumed as constantly active or at rest, which is different with reality. Although the increase in the number of elements can solve the complex mechanical behavior of the steel sheet pile, the numerical modeling procedure and calculation will be much more complicated and time-consuming.

In practical engineering, many empirical with linear assumptions are widely introduced to describe the structural behaviors of the steel sheet pile with only considering a constant soil stiffness [22]. Besides, the effective length method based on Euler's theory of column buckling (Fig.1 (b)), which identifies the buckling behavior of steel sheet pile by different safety factors under different boundary conditions, is still the most common solution, like Eurocode 3 [23]. However, these simplifications cannot accurately consider the nonlinear SSI and the second-order effect of steel sheet piles to evaluate their complicated structural behaviors.

To overcome these limitations in numerical and practical design methods, recently, Liu et al. [24] proposed a new line element based on Euler-Bernoulli beam-column theory, named pile element, as shown in Fig. 3 (c). This new proposed pile element has a high computational efficiency, where the soil response is directly incorporated into the beam element. This pile element is not required to consider the soil spring elements and can accurately evaluate the nonlinear SSI. Li et al. [25] extended this pile element to study the pile with nonlinearly varying soil stiffness under different boundary conditions with reasonable results. In the present paper, the pile element will be developed to directly include soil springs in front of the pile in the analysis of steel sheet piles. Meanwhile, the realistic distribution of soil pressure behind the pile can be considered and evaluated.

In this paper, the detailed derivation of the developed pile element can be seen in the second part. Then, the selected lateral and axial shape functions will be introduced to derive the total potential energy formula. Using the Gauss-Legendre method, $p-y, t-z$ relationships, and the soil pressure behind the pile can be directly described. A semi-analytical solution of the stiffness matrix and secant relations will be obtained and incorporated with the Newton-Raphson incremental-iterative numerical procedure through the variation of the total potential energy, where the computational errors of the nonlinear iteration and large deformation can be eliminated. Finally, three benchmark examples are present to verify the accuracy and efficiency of the developed pile element. Comparison studies include the analytical method and the discrete spring method. In addition, the lateral pressure on the behind of the pile is explored to consider the active, at rest, and realistic distributions.

\section{Assumptions in pile element formulation}

The assumptions in the pile element formulation are made in here: a. warping and shear deformations will be ignored; b. loads on the element are conservative;

c. the material of the pile is isotropic, homogeneous and linear elastic, which means Hooke's material law [26] can be introduced;

d. the Euler-Bernoulli assumption is introduced in element formulation; e. strains are small, meanwhile, displacement can be moderately large.

\section{Pile element formulations}

\subsection{Shape functions of pile-element}

For describing the deformation along the element, the axial and lateral deflection of the element are given as:

$$
\begin{aligned}
u(x) & =\left(-\frac{x}{L}+1\right) u_{1}+\frac{x}{L} u_{2} \\
v(x) & =\left[2\left(\frac{x}{L}\right)^{3}-3\left(\frac{x}{L}\right)^{2}+1\right] v_{1}+\left[-\left(\frac{x}{L}\right)^{2}-2 \frac{x}{L}+1\right] x \theta_{1} \\
& +\left[-2\left(\frac{x}{L}\right)^{3}+3\left(\frac{x}{L}\right)^{2}\right] v_{2}+\left[\left(\frac{x}{L}\right)^{2}-\frac{x}{L}\right] x \theta_{2}
\end{aligned}
$$

where $u$ and $v$ are the value of the axial and the lateral deflections along the element, respectively; and $u_{1}, u_{2}, v_{l}, v_{2}, \theta_{l}$ and $\theta_{2}$ are the displacement at two different sides of the element, which are all plotted in Fig. 4. 


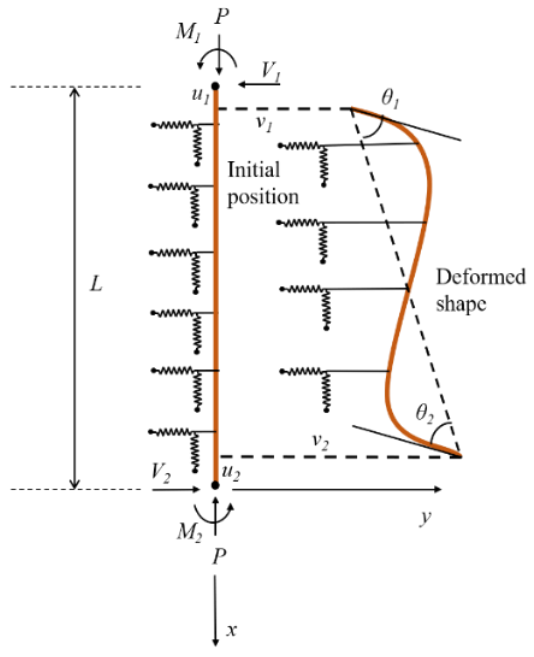

Fig. 4 Element forces and displacements

\subsection{Total energy function of the element}

To getting the tangent stiffness matrix and the secant relations of the element, the total energy of the element, $\Pi$, is given as:

$$
\Pi=U_{E}+U_{S}+W_{P}+W_{S}
$$

where $U_{E}$ and $U_{s}$ are the energy accumulating in the pile and the surrounding medium, respectively; $W_{P}$ and $W_{s}$ are the work done by the force at the nodes of the elements and the distributed soil pressure behind the steel sheet pile, respectively.

The strain energy of the pile can be given as:

$U_{E}=\frac{1}{2} \int_{V}\left(\sigma_{x} \varepsilon_{x}+\tau_{x y} \varepsilon_{x y}\right) d V$

By introducing Green-Lagrangian strain theory and Hooke's material law [26] into Eq.4 when ignoring the high order terms, $U_{E}$ can be rewritten as:

$$
\begin{aligned}
U_{E} & =\frac{1}{2} \int_{0}^{L}\left[E A\left(\frac{\partial u(x)}{\partial x}\right)^{2}+E A\left(\frac{\partial v^{2}(x)}{\partial x^{2}}\right)^{2}\right] d x \\
& +\frac{1}{2} \int_{0}^{L} P\left(\frac{\partial v(x)}{\partial x}\right)^{2} d x-\int_{0}^{L} \frac{V}{A}\left(\frac{\partial u(x)}{\partial x} \frac{\partial v(x)}{\partial x}\right) d v
\end{aligned}
$$

The energy absorbed by soil can be separated into two parts, which are:

$$
U_{S}=U_{S P}+U_{S \tau}
$$

where $U_{S P}$ and $U_{S \tau}$ are the energy consumed by the lateral soil resistance and shaft resistance, respectively. And their expression can be given as:

$U_{S P}=\int_{0}^{L} \int_{0}^{v} p(v) d v d x$

$$
U_{S \tau}=\int_{0}^{L} \int_{0}^{u} t(u) d u d x
$$

where $p$ and $t$ are the lateral and shaft resistance per unit along the element, which can be given according to $p-y$ and $t-z$ curve, respectively. However, due to the complex expression of $p-y$ and $t-z$ curve of the sheet pile, the analytical solutions of the Eqs.7 $\sim 8$ are difficult to be given. For this reason, the Gauss-Legendre method is adopted for simplified the expressions of $U_{S P}$ and $U_{S \tau}$. Thus, the energy absorbed by soil can be rewritten as:

$U_{S P} \approx \frac{1}{2} \sum_{i=1}^{n} H_{i} k_{p}\left(v_{i}\right) v_{i}^{2}$

$$
U_{S t} \approx \frac{1}{2} \sum_{i=1}^{n} H_{i} k_{t}\left(u_{i}\right) u_{i}^{2}
$$

where $k_{p}(v)$ and $k_{t}(u)$ are the tangential values of $p$-y and $t$-z curve at some specified deflections; $n$ is number of Gaussian points, respectively; $v_{i}$ and $u_{i}$ are the lateral and axial deflection at the $i^{\text {th }}$ Gaussian point, respectively; $H_{i}$ is weight of the $i^{\text {th }}$ Gaussian point.

The work done by the force at the nodes of the element can be written as:

$W_{P}=P u_{1}+M_{1} \theta_{1}+V_{1} v_{1}-P u_{2}+M_{2} \theta_{2}+V_{2} v_{2}$

And the work done by the distributed soil pressure can be given as:

$W_{S}=\int_{0}^{L} \int_{0}^{v} q(v) d v d x$

where $q$ is the lateral pressure per unit along the element, which is varied with $x$ and $v$. Similarly, using the Gauss-Legendre method, $W_{S}$ can be simplified as:

$W_{S} \approx \frac{1}{2} \sum_{i=1}^{n} H_{i} k_{q}\left(v_{i}\right) v_{i}^{2}$

where $k_{q}(v)$ is the tangential value of the function of soil pressure.

\subsection{Tangent stiffness matrix of the element}

For describing the deformation process of the element, the tangent stiffness matrix is given by using the second-order variation of the total energy function, $\Pi$ :

$$
\delta \Pi=\frac{\partial^{2} \Pi_{i}}{\partial u_{i} \partial u_{j}} \delta u_{i} \delta u_{j}
$$

Thus, the stiffness matrix of the element can be divided into four parts as:

$[k]_{E}=[k]_{L}+[k]_{G}+[k]_{S R}+[k]_{S q}$

where $[k]_{E}$ is the tangent stiffness matrix of the whole pile element; $[k]_{L}$ is the linear stiffness matrix; $[k]_{G}$ is the geometric stiffness matrix; $[k]_{S R}$ is the soil resistance stiffness matrix; and $[k]_{S q}$ is the soil pressure stiffness matrix.

The linear stiffness matrix, $[k]_{E}$, can be written as:

$[k]_{L}=\left[\begin{array}{cccccc}\frac{E A}{L} & 0 & 0 & -\frac{E A}{L} & 0 & 0 \\ 0 & 12 \frac{i}{L^{2}} & 6 \frac{i}{L} & 0 & -12 \frac{i}{L^{2}} & 6 \frac{i}{L} \\ 0 & 6 \frac{i}{L} & 4 i & 0 & -6 \frac{i}{L} & 2 i \\ -\frac{E A}{L} & 0 & 0 & \frac{E A}{L} & 0 & 0 \\ 0 & -12 \frac{i}{L^{2}} & 6 \frac{i}{L} & 0 & 12 \frac{i}{L^{2}} & -6 \frac{i}{L} \\ 0 & -6 \frac{i}{L} & 2 i & 0 & -6 \frac{i}{L} & 4 i\end{array}\right]$

Where

$i=\frac{E I}{L}$

The geometric stiffness matrix, $[k]_{G}$, can be written as: 
Table 1

Coefficients $A_{j i}$ and $B_{j i}$ in the stiffness matrix

\begin{tabular}{|c|c|c|c|c|c|c|c|c|c|}
\hline Gaussian points & 1 & 2 & 3 & 4 & 5 & 6 & 7 & 8 & 9 \\
\hline Location & 0.01592 & 0.08198 & 0.19331 & 0.33787 & 0.50000 & 0.66213 & 0.80669 & 0.91802 & 0.98408 \\
\hline$A_{1 i}$ & 0.03935 & 0.07612 & 0.08480 & 0.06847 & 0.04128 & 0.01783 & 0.00487 & 0.00061 & 0.00001 \\
\hline$A_{2 i}$ & 0.00064 & 0.00680 & 0.02032 & 0.03494 & 0.04128 & 0.03494 & 0.02032 & 0.00680 & 0.00064 \\
\hline$A_{3 i}$ & 0.00001 & 0.00061 & 0.00487 & 0.01783 & 0.04128 & 0.06847 & 0.08480 & 0.07612 & 0.03935 \\
\hline$B_{1 i}$ & 0.04058 & 0.08691 & 0.10610 & 0.08429 & 0.04128 & 0.01099 & 0.00124 & 0.00003 & 0.00000 \\
\hline$B_{2 i}$ & 0.00063 & 0.00602 & 0.01309 & 0.00814 & -0.01032 & -0.02093 & -0.01298 & -0.00265 & -0.00006 \\
\hline$B_{3 i}$ & 0.00003 & 0.00169 & 0.01148 & 0.03044 & 0.04128 & 0.03044 & 0.01148 & 0.00169 & 0.00003 \\
\hline$B_{4 i}$ & 0.00001 & 0.00064 & 0.00524 & 0.01752 & 0.03096 & 0.03020 & 0.01496 & 0.00278 & 0.00006 \\
\hline$B_{5 i}$ & 0.00001 & 0.00042 & 0.00162 & 0.00079 & 0.00258 & 0.03983 & 0.13550 & 0.21453 & 0.14759 \\
\hline$B_{6 i}$ & 0.00000 & 0.00012 & 0.00142 & 0.00294 & -0.01032 & -0.05794 & -0.11990 & -0.13655 & -0.07739 \\
\hline$B_{7 i}$ & 0.00000 & 0.00004 & 0.00065 & 0.00169 & -0.00774 & -0.05747 & -0.15622 & -0.22501 & -0.14880 \\
\hline$B_{8 i}$ & 0.00000 & 0.00000 & 0.00000 & 0.00000 & 0.00000 & 0.00025 & 0.00239 & 0.00416 & 0.00089 \\
\hline$B_{9 i}$ & 0.00000 & 0.00001 & 0.00057 & 0.00633 & 0.03096 & 0.08361 & 0.13824 & 0.14322 & 0.07802 \\
\hline$B_{10 i}$ & 0.00000 & 0.00000 & 0.00026 & 0.00364 & 0.02322 & 0.08293 & 0.18011 & 0.23600 & 0.15003 \\
\hline
\end{tabular}

$[k]_{G}=\left[\begin{array}{cccccc}\frac{P}{L} & -\frac{M_{1}+M_{2}}{L^{2}} & 0 & -\frac{P}{L} & \frac{M_{1}+M_{2}}{L^{2}} & 0 \\ -\frac{M_{1}+M_{2}}{L^{2}} & \frac{6 P}{5 L} & \frac{P}{10} & \frac{M_{1}+M_{2}}{L^{2}} & -\frac{6 P}{5 L} & \frac{P}{10} \\ 0 & \frac{P}{10} & \frac{2 P L}{15} & 0 & -\frac{P}{10} & -\frac{P L}{30} \\ -\frac{P}{L} & \frac{M_{1}+M_{2}}{L^{2}} & 0 & \frac{P}{L} & -\frac{M_{1}+M_{2}}{L^{2}} & 0 \\ \frac{M_{1}+M_{2}}{L^{2}} & -\frac{6 P}{5 L} & -\frac{P}{10} & -\frac{M_{1}+M_{2}}{L^{2}} & \frac{6 P}{5 L} & -\frac{P}{10} \\ 0 & \frac{P}{10} & -\frac{P L}{30} & 0 & -\frac{P}{10} & \frac{2 P L}{15}\end{array}\right]$

The soil resistance stiffness matrix, $[k]_{S R}$, can be written as:

$$
[k]_{S R}=\left[\begin{array}{cccccc}
\sum_{i=1}^{n} A_{1 i} k_{t i} L & 0 & 0 & \sum_{i=1}^{n} A_{2 i} k_{t i} L & 0 & 0 \\
0 & \sum_{i=1}^{n} B_{1 i} k_{p i} L & \sum_{i=1}^{n} B_{2 i} k_{p i} L^{2} & 0 & \sum_{i=1}^{n} B_{3 i} k_{p i} L & \sum_{i=1}^{n} B_{4 i} k_{p i} L^{2} \\
0 & \sum_{i=1}^{n} B_{2 i} k_{p i} L^{2} & \sum_{i=1}^{n} B_{5 i} k_{p i} L^{3} & 0 & \sum_{i=1}^{n} B_{6 i} k_{p i} L^{2} & \sum_{i=1}^{n} B_{7 i} k_{p i} L^{3} \\
\sum_{i=1}^{n} A_{2 i} k_{t i} L & 0 & 0 & \sum_{i=1}^{n} A_{3 i} k_{t i} L & 0 & 0 \\
0 & \sum_{i=1}^{n} B_{3 i} k_{p i} L & \sum_{i=1}^{n} B_{6 i} k_{p i} L^{2} & 0 & \sum_{i=1}^{n} B_{8 i} k_{p i} L & \sum_{i=1}^{n} B_{9 i} k_{p i} L^{2} \\
0 & \sum_{i=1}^{n} B_{4 i} k_{p i} L^{2} & \sum_{i=1}^{n} B_{7 i} k_{p i} L^{3} & 0 & \sum_{i=1}^{n} B_{9 i} k_{p i} L^{2} & \sum_{i=1}^{n} B_{10 i} k_{p i} L^{3}
\end{array}\right]
$$

where $k_{t i}$ and $k_{p i}$ denote $k_{p}\left(v_{\mathrm{i}}\right)$ and $k_{t}\left(u_{i}\right)$, respectively; and $A_{j i}$ and $B_{j i}$ are the corresponding coefficients, which are given in Table 1 .

Accordingly, the soil pressure stiffness matrix, $[k]_{S q}$, can be given as:

$$
[k]_{S q}=\left[\begin{array}{cccccc}
0 & 0 & 0 & 0 & 0 & 0 \\
0 & \sum_{i=1}^{n} B_{1 i} k_{q i} L & \sum_{i=1}^{n} B_{2 i} k_{q i} L^{2} & 0 & \sum_{i=1}^{n} B_{3 i} k_{q i} L & \sum_{i=1}^{n} B_{4 i} k_{q i} L^{2} \\
0 & \sum_{i=1}^{n} B_{2 i} k_{q i} L^{2} & \sum_{i=1}^{n} B_{5 i} k_{q i} L^{3} & 0 & \sum_{i=1}^{n} B_{6 i} k_{q i} L^{2} & \sum_{i=1}^{n} B_{7 i} k_{q i} L^{3} \\
0 & 0 & 0 & 0 & 0 & 0 \\
0 & \sum_{i=1}^{n} B_{3 i} k_{q i} L & \sum_{i=1}^{n} B_{6 i} k_{q i} L^{2} & 0 & \sum_{i=1}^{n} B_{8 i} k_{q i} L & \sum_{i=1}^{n} B_{9 i} k_{q i} L^{2} \\
0 & \sum_{i=1}^{n} B_{4 i} k_{q i} L^{2} & \sum_{i=1}^{n} B_{7 i} k_{q i} L^{3} & 0 & \sum_{i=1}^{n} B_{9 i} k_{q i} L^{2} & \sum_{i=1}^{n} B_{10 i} k_{q i} L^{3}
\end{array}\right]
$$

where $k_{q i}$ denotes $k_{q}\left(v_{\mathrm{i}}\right)$.

3.4. Secant relations of the element
For eliminating the error accumulating in the iterative procedure, the secant relations of the element are elicited by the minimum potential energy method as:

$\frac{\partial \Pi}{\partial u_{i}}=0$

And the resisting force on the element can be divided into two parts: the force from the element deformation and the SSIs of the sheet pile. Thus, the total resisting force vector, $\left\{F_{T}\right\}$, can be expressed as:

$\left\{F_{T}\right\}=\left\{\begin{array}{l}F_{E x 1} \\ F_{E y 1} \\ M_{E 1} \\ F_{E x 2} \\ F_{E y 2} \\ M_{E 2}\end{array}\right\}+\left\{\begin{array}{c}F_{S x 1} \\ F_{S y 1} \\ M_{S 1} \\ F_{S x 2} \\ F_{S y 2} \\ M_{S 2}\end{array}\right\}$

where $F_{x 1}$ and $F_{x 2}$ are the forces along the $x$-axis at the two sides of the pile element; $F_{y l}$ and $F_{y 2}$ are the forces along the $y$-axis at the two sides of the pile element; $M_{1}$ and $M_{2}$ are the bending moments at the two sides of the pile element; and the subscripts ${ }_{E}$ and ${ }_{S}$ denote the resisting forces from the element deformation and the SSIs relationships.

The first part of $\left\{F_{T}\right\}$ can be given as:

$F_{E x 1}=\frac{E A}{L}\left(u_{1}-u_{2}\right)+\frac{\left(M_{1 E}+M_{2 E}\right)}{L^{2}}\left(-v_{1}+v_{2}\right)$

$F_{E x 2}=\frac{E A}{L}\left(-u_{1}+u_{2}\right)+\frac{\left(M_{1 E}+M_{2 E}\right)}{L^{2}}\left(v_{1}-v_{2}\right)$

$F_{E y 1}=\frac{\left(M_{1 E}+M_{2 E}\right)}{L^{2}}\left(-u_{1}+u_{2}\right)+\frac{12 E I}{L^{3}}\left(v_{1}-v_{2}\right)+\frac{6 E I}{L^{2}}\left(\theta_{1}+\theta_{2}\right)$

$+\frac{6 P}{5 L}\left(v_{1}-v_{2}\right)+\frac{P}{10}\left(\theta_{1}-\theta_{2}\right)$

$F_{E y 2}=\frac{\left(M_{1 E}+M_{2 E}\right)}{L^{2}}\left(u_{1}-u_{2}\right)+\frac{12 E I}{L^{3}}\left(-v_{1}+v_{2}\right)+\frac{6 E I}{L^{2}}\left(-\theta_{1}-\theta_{2}\right)$

$+\frac{6 P}{5 L}\left(-v_{1}+v_{2}\right)+\frac{P}{10}\left(-\theta_{1}-\theta_{2}\right)$

$M_{E 1}=\frac{6 E I}{L^{2}}\left(v_{1}-v_{2}\right)+\frac{2 E I}{L}\left(2 \theta_{1}+\theta_{2}\right)+\frac{P}{10}\left(v_{1}-v_{2}\right)+\frac{L P}{30}\left(4 \theta_{1}-\theta_{2}\right)$

$M_{E 2}=\frac{6 E I}{L^{2}}\left(v_{1}-v_{2}\right)+\frac{2 E I}{L}\left(\theta_{1}+2 \theta_{2}\right)+\frac{P}{10}\left(v_{1}-v_{2}\right)+\frac{L P}{30}\left(-\theta_{1}+4 \theta_{2}\right)$ 
Table 2

Coefficients $C_{j i}, D_{j i}$ and $O_{j i}$ in the secant relations

\begin{tabular}{|c|c|c|c|c|c|c|c|c|c|}
\hline Gaussian points & 1 & 2 & 3 & 4 & 5 & 6 & 7 & 8 & 9 \\
\hline Location & 0.01592 & 0.08198 & 0.19331 & 0.33787 & 0.50000 & 0.66213 & 0.80669 & 0.91802 & 0.98408 \\
\hline$C_{1 i}$ & 0.03999 & 0.08292 & 0.10512 & 0.10341 & 0.08256 & 0.05277 & 0.02519 & 0.00741 & 0.00065 \\
\hline$C_{2 i}$ & 0.00065 & 0.00741 & 0.02519 & 0.05277 & 0.08256 & 0.10341 & 0.10512 & 0.08292 & 0.03999 \\
\hline$D_{1 i}$ & 0.04061 & 0.08860 & 0.11758 & 0.11474 & 0.08256 & 0.04144 & 0.01273 & 0.00172 & 0.00003 \\
\hline$D_{2 i}$ & 0.00003 & 0.00172 & 0.01273 & 0.04144 & 0.08256 & 0.11474 & 0.11758 & 0.08860 & 0.04061 \\
\hline$O_{1 i}$ & 0.00063 & 0.00624 & 0.01639 & 0.02313 & 0.02064 & 0.01180 & 0.00393 & 0.00056 & 0.00001 \\
\hline$O_{2 i}$ & 0.00001 & 0.00056 & 0.00393 & 0.01180 & 0.02064 & 0.02313 & 0.01639 & 0.00624 & 0.00063 \\
\hline
\end{tabular}

By using the Gauss-Legendre method, the second parts of $\left\{F_{T}\right\}$ can be simplified and written as:

$$
F_{s x 1}=\int_{L}\left(1-\frac{x}{L}\right) t(x) d x \approx L \sum_{i=1}^{n} C_{1 i} t\left(x_{i}\right)
$$

$$
F_{S x 2}=\int_{L} \frac{x}{L} t(x) d x \approx L \sum_{i=1}^{n} C_{2 i} t\left(x_{i}\right)
$$

$$
\begin{aligned}
F_{S 1 y} & =\int_{0}^{L}\left(\frac{3 x}{L}+\frac{L-x}{L}\right)\left(1-\frac{x}{L}\right)^{2}[p(x)+q(x)] d x \\
& \approx L \sum_{i=1}^{n} D_{1 i}\left[p\left(x_{i}\right)+q\left(x_{i}\right)\right]
\end{aligned}
$$

$$
\begin{aligned}
F_{S 2 y} & =-\int_{0}^{L}\left[\frac{x}{L}+\frac{3(L-x)}{L}\right]\left(\frac{x}{L}\right)^{2}[p(x)+q(x)] d x \\
& \approx-L \sum_{i=1}^{n} D_{2 i}\left[p\left(x_{i}\right)+q\left(x_{i}\right)\right]
\end{aligned}
$$

$M_{S 1}=\int_{0}^{L} x\left(1-\frac{x}{L}\right)^{2}[p(x)+q(x)] d x \approx L^{2} \sum_{i=1}^{n} O_{1 i}\left[p\left(x_{i}\right)+q\left(x_{i}\right)\right]$

$M_{S 2}=-\int_{0}^{L} \frac{x^{2}}{L^{2}}(L-x)[p(x)+q(x)] d x \approx-L^{2} \sum_{i=1}^{n} O_{2 i}\left[p\left(x_{i}\right)+q\left(x_{i}\right)\right]$

where $C_{j i}, D_{j i}$ and $O_{j i}$ are the corresponding coefficients which are all given in Table 2 .

\section{Newton-raphson typed numercial procedure for pile element}

For describing the large deformation process,[27], Updated- Lagrangian (UL) method [28, 29] have been adopted in the numerical procedure. By using UL method, the equilibrium condition can be established according to the last-known element location in the iterative procedure (as shown in Fig. 5).

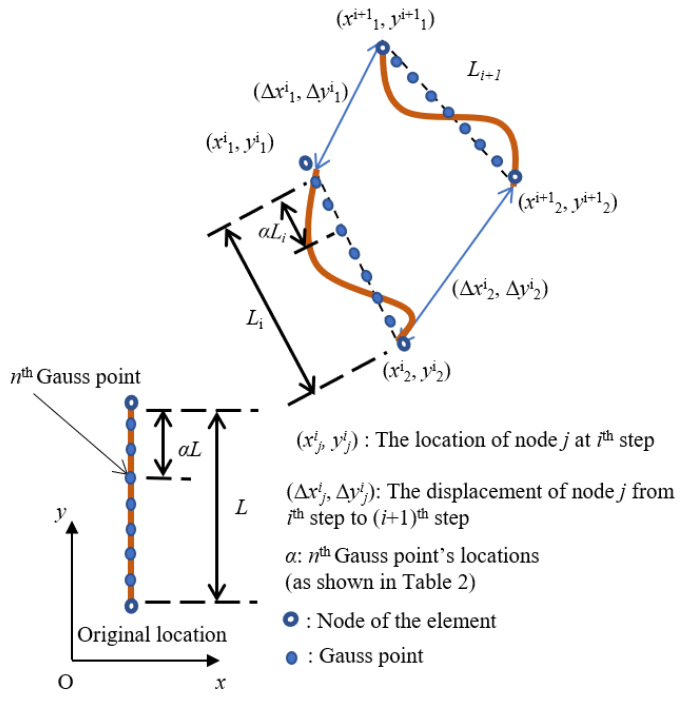

Fig. 5 Schematic of Updated- Lagrangian method for pile element

Therefore, the element stiffness matrix can be converted accordingly before assembling it into the global stiffness matrix, $[k]$, which can be given as:

$[k]=\sum_{i=1}^{N}[\gamma]_{i}[k]_{E}[\gamma]_{i}^{T}$

where $[\gamma]_{i}$ is the transformation matrix for describing the initial position of the pile element during the $i^{\text {th }}$ step; and $N$ is the total number of the pile elements.

For eliminating the error accumulating in the nonlinear calculation, a new incremental-iterative procedure is proposed based on Newton-Raphson procedure [30] to integrated UL method and element formulation. And the flowchart is plotted in Fig. 6. Also the displacements and unbalanced forces are selected as the converge criterion in this paper to obtain an accurate result. Meanwhile, UL method and Newton-Raphson incremental-iterative procedure have been widely adopted in structural analysis and their robustness have been proven [24, 31-33]. 


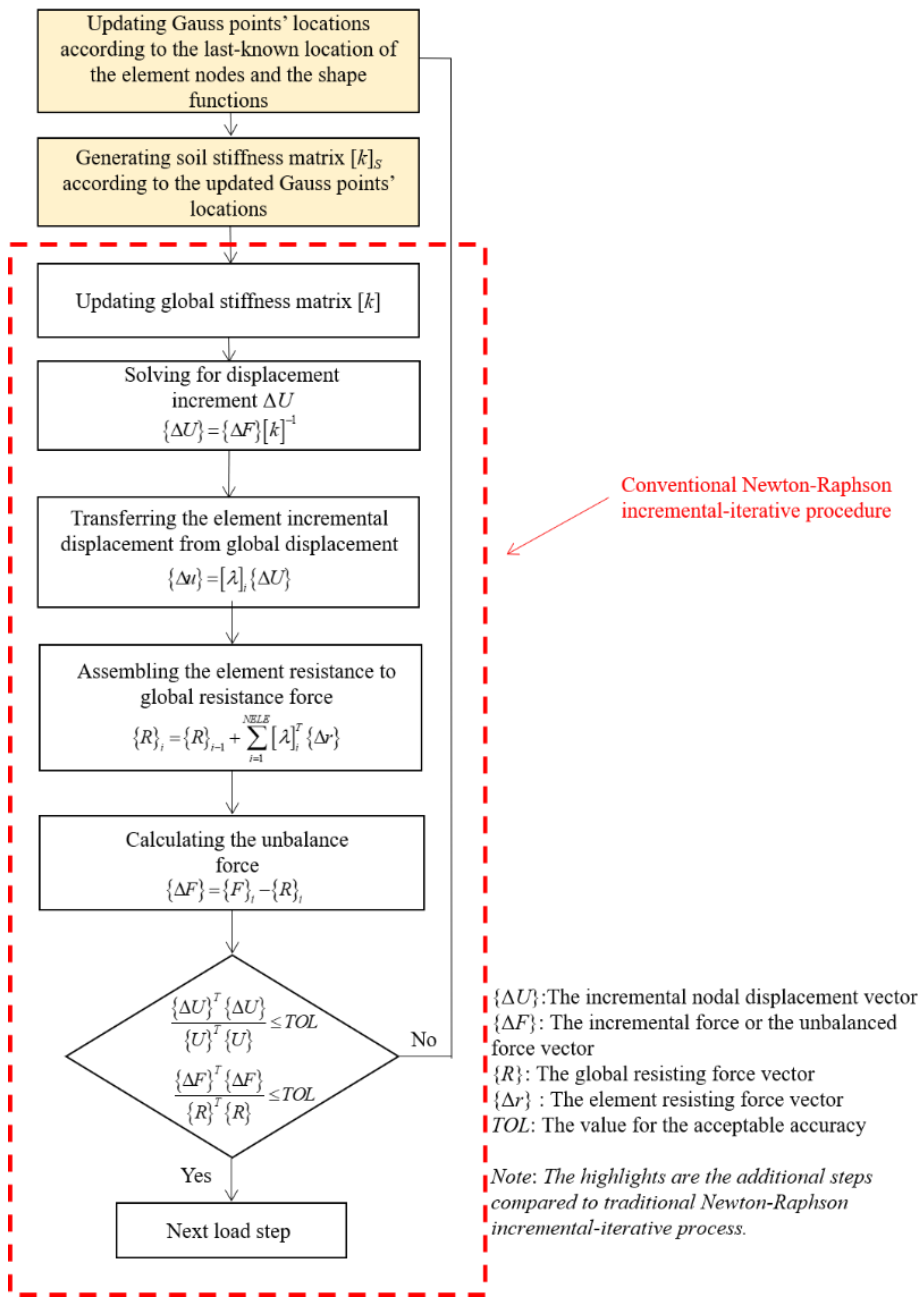

Fig. 6 Flowchart of the Newton-Raphson typed incremental-iterative procedure

\section{Verification examples}

In this section, three examples are presented to verify the accuracy and efficiency of the developed pile element.

\subsection{Example 1-The buckling behaviour of steel sheet pile in elastic medium}

Steel sheet piles are easily to be installed but with a lower strength. Their failure behaviors are usually determined by the buckling strength, $F_{c r}$, which has been evaluated by some analytical and semi-analytical methods with the linear assumption. Assuming the pile top and toe are pinned, only the vertical load is applied on the pile top, where the shaft resistance is ignored, the analytical solution of $F_{c r}$ can be seen as follow:

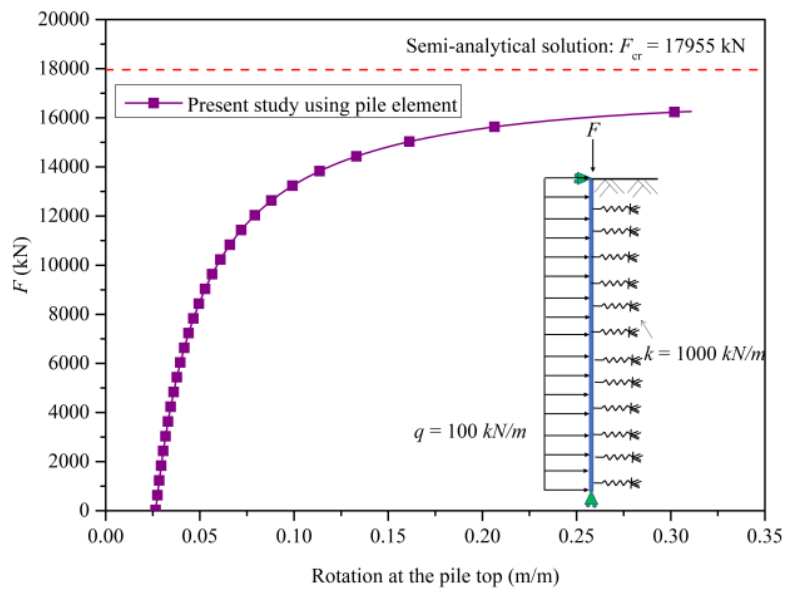

(a) Comparison of the result with the semi-analytical solution and pile element under load condition A

$$
F_{c r}=\frac{\pi^{2} E I}{L^{2}}+k \frac{L^{2}}{\pi^{2}}
$$

where $F_{c r}$ is the critical buckling load; $E I$ and $L$ are the flexural rigidity and the length of the sheet pile, respectively; and $k$ is the lateral stiffness of the soil.

In order to consider the horizontal loads and the bending moment, Vincent [34] proposed a semi-analytical solution to consider the buckling behavior of the steel sheet pile wall. Details can be seen

$$
F_{c r}=\frac{\frac{w^{I I}}{w^{I}}+\delta}{\frac{w^{I I}}{w^{I}}-1} N
$$

where $N$ is the vertical load on the pile top; $w^{I}$ and $w^{I I}$ are the first-order and second-order lateral displacements at the middle of the pile, respectively; and $\delta$ is an empirical coefficient which can be found in [34].

In this example, the cross section AZ18-700 of the steel sheet pile is selected to verify the developed pile element with analytical and semi-analytical methods. The steel sheet pile is $10 \mathrm{~m}$ long with a unit cross section $1.392 \times 10^{-2} \mathrm{~m}^{-2}$ and an inertia moment $3.780 \times 10^{-4} \mathrm{~m}^{-4}$. Detailed load and boundary conditions can be seen in Fig. 7 and Fig. 8 .

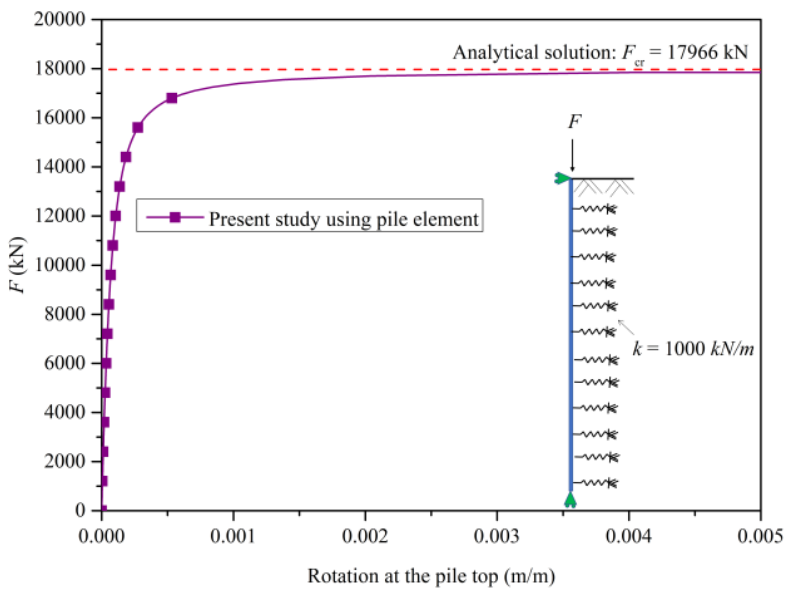

Fig. 7 Comparison of the result with the analytical solution and pile elemen

It can be found that the analytical solution can match well with the developed pile element. However, there still exists a difference with the semi-analytical method when the horizontal loads and bending moment are considered. This may be induced by the pile compression is ignored by the semi-analytical method. This difference also hints that the bucking behavior of steel sheet pile is extremely complicated even within the linear elastic condition. Hence, it is necessary to introduce the advanced finite element to simulate the structural buckling behavior.



(b) Comparison of the result with the semi-analytical solution and pile element under load condition B 


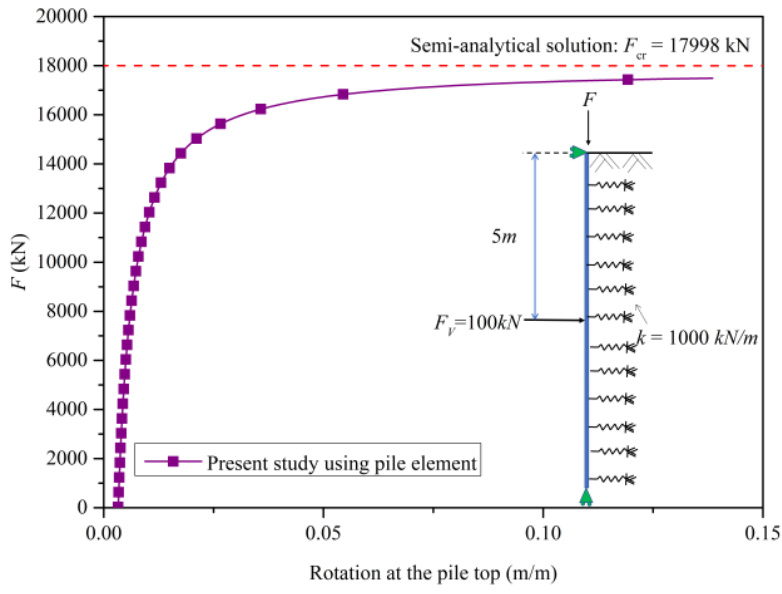

(c) Comparison of the result with the semi-analytical solution and pile element under load condition $\mathrm{C}$

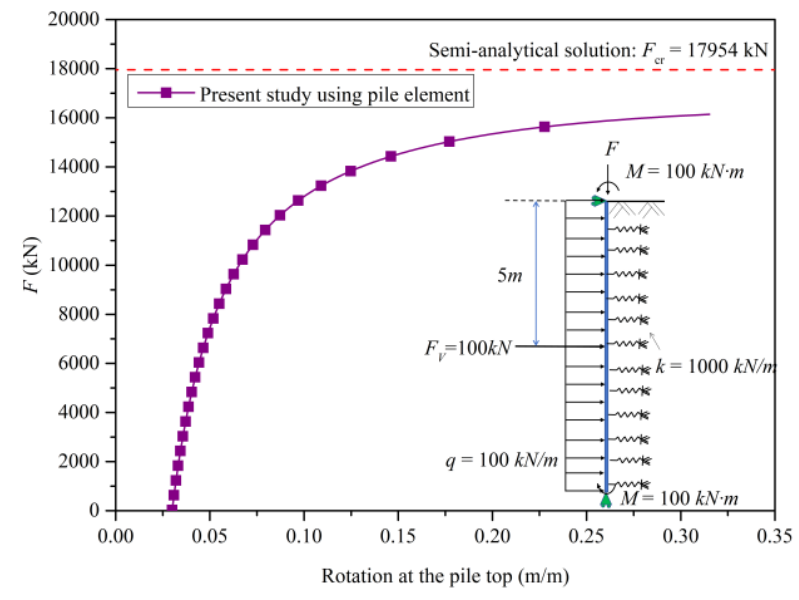

(d) Comparison of the result with the semi-analytical solution and pile element under load condition D

Fig. 8 Comparison of the result with the semi-analytical solution and pile element under different load conditions

\subsection{Example 2-The deformation and buckling of the steel sheet pile} considering nonlinear SSI

In practical engineering, the soil surrounding the steel sheet pile is always assumed with a constant stiffness in the analysis of the pile's second-order effect[22]. However, soil as a natural discrete material its stiffness can be highly influenced by the depth and the relative displacement between pile and soil. For accurately considering the nonlinear SSI, the $p-y$ curve is incorporated the linear elastic spring model by many investigations [18, 21]. In this example, the developed pile element is considered to compare with the discrete spring element to verify its accuracy and efficiency with the consideration of nonlinear SSI. Similar as Example 1, the steel sheet pile AZ18-700 is selected to study the deformation and buckling process with the pile cap load and lateral active pressure. The steel sheet pile is $10 \mathrm{~m}$ long, with a unit pile soil contact area $2.574 \mathrm{~m}^{2}$, a unit cross section $1.392 \times 10^{-2} \mathrm{~m}^{2}$ and an inertial moment $3.780 \times 10^{-4} \mathrm{~m}^{4}$. The elastic modulus of the pile is $2.06 \times 10^{8}$ $\mathrm{kPa}$. Soil properties and loading conditions can be seen in Fig. 9. Meanwhile, the related $p-y$ curve and $t-z$ curve will be followed by previous studies $[17,18]$ and plotted in Fig. 10.

It can be found in Fig. 11 that the developed pile element model with 10 elements can obtain a similar result with the conventional discrete spring element with 50 beam elements and 75 soil spring elements. That means the discrete spring element will require more than 5 times of the proposed element to obtain a nearly accurate solution. As known, the element number can dramatically increase the modelling procedure and time. Hence, the present pile element with high accuracy and efficiency has a huge potential in the practical design of the steel sheet pile wall.

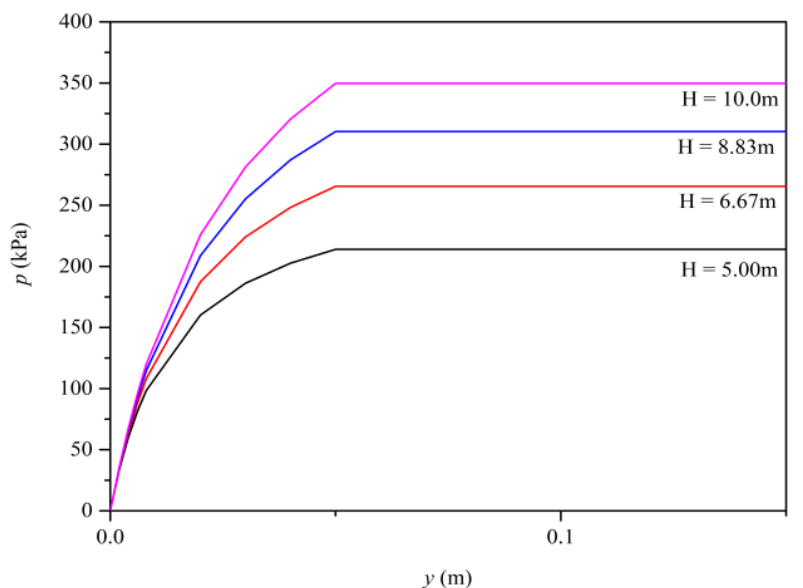

(a) $p-y$ curve of the sheet pile in Example 2

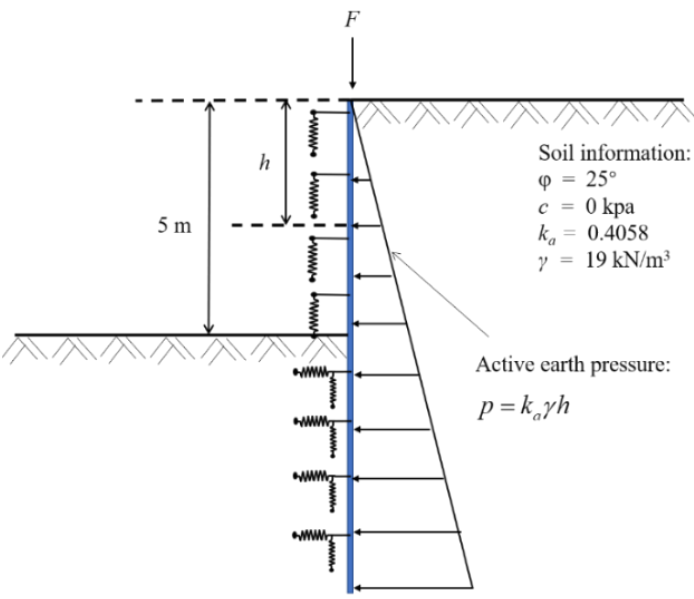

Fig. 9 Schematic of the sheet pile in Example 2

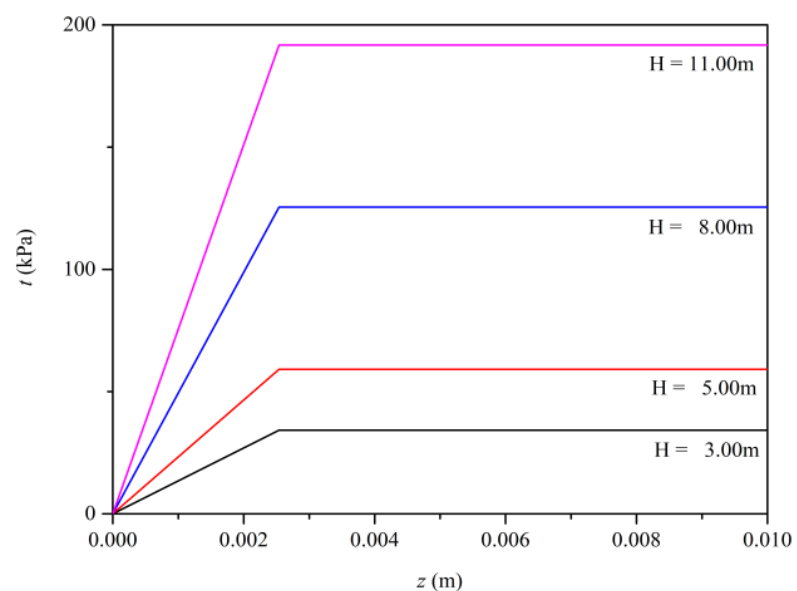

(b) $t-z$ curve of the sheet pile in Example 2

Fig. $10 p-y$ and $t-z$ curves of the sheet piles in Example 2 


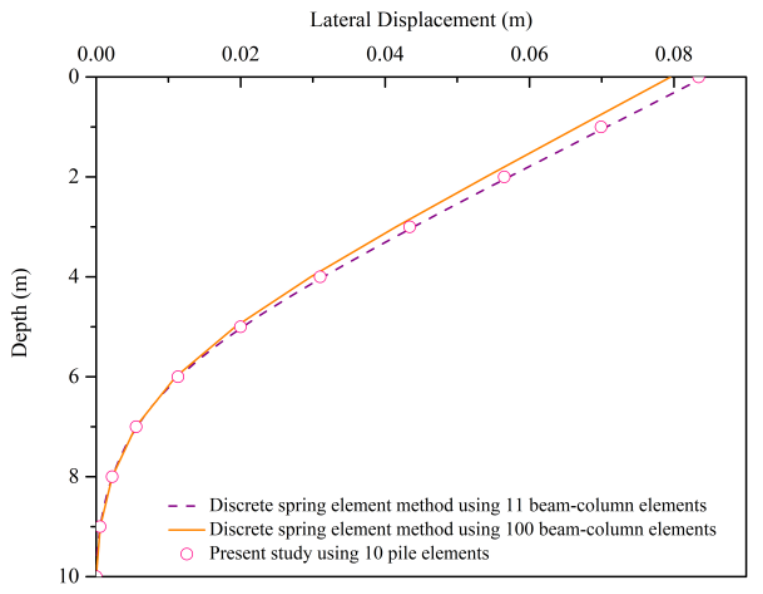

(a) The lateral deflection of the sheet pile when $F=450 \mathrm{kN}$

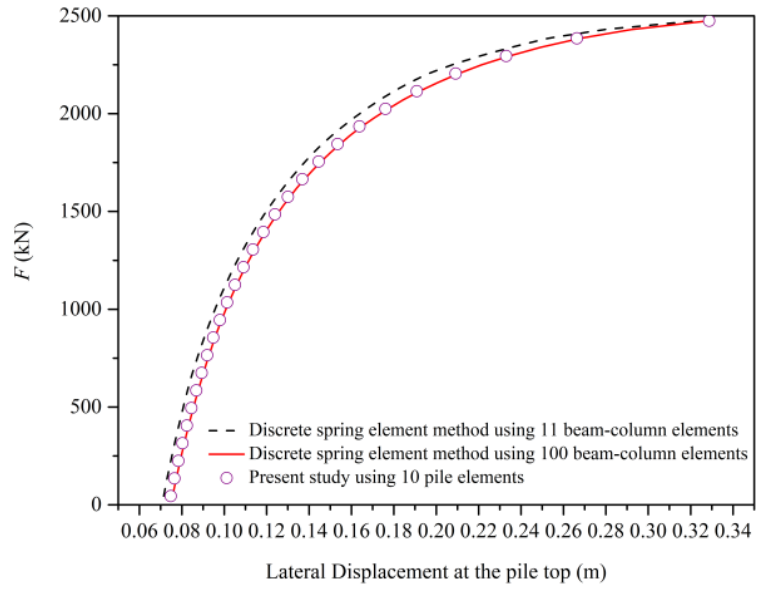

(b) The lateral displacement at the pile top under different load at the pile's top

Fig. 11 Comparison of different finite element models when simulating the deformation and buckling of the sheet pile

5.3. Example 3-The deformation and bearing capacity of the steel sheet pile wall with the consideration of the realistic soil pressure distribution

The passive and active lateral pressures are unbalanced in front of and behind the steel sheet pile. The soil resistance in front of the steel sheet pile can be described by the $p-y$ curve, which can be introduced into the discrete element method to simulate the lateral pressure from the rest to passive [21]. However, for the soil pressure behind the pile, it usually adopts the factor of safety to combine with the rest or active lateral pressure, where the realistic variation of the active lateral pressure is ignored. This will induce a large numerical error.

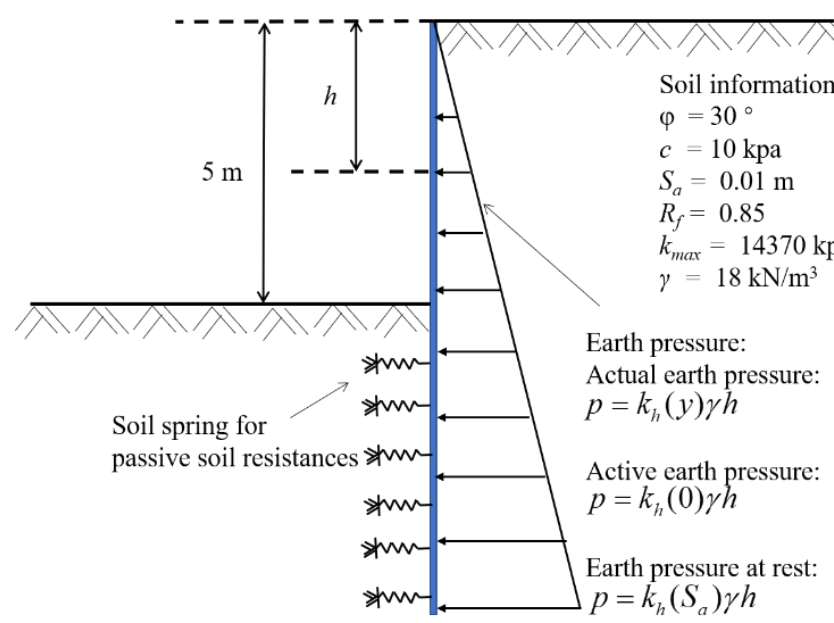

Fig. 12 Schematic of the steel sheet pile in Example 3

In this example, the present pile element will be used to mimic the realistic variation of lateral pressure behind the pile. Comparisons are carried out with the rest and active lateral pressures. Also the selected steel sheet pile AZ28-700 is $10 \mathrm{~m}$ long, with a unit inertial moment $6.362 \times 10^{-4} \mathrm{~m}^{4}$ and a cross section $2.002 \times 10^{-2} \mathrm{~m}^{2}$. The elastic modulus of the steel sheet pile is $2.100 \times 10^{8} \mathrm{GPa}$. Soil properties can be found in Fig. 12. In this example, the variation of lateral pressure with the deformation is selected from previous studies $[17,35]$.

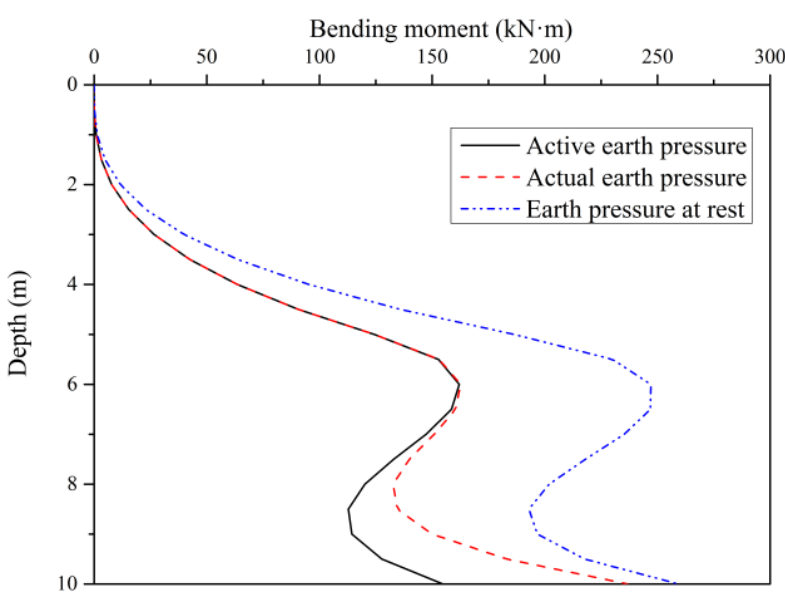

(a) The bending moment along the sheet pile under different earth pressure

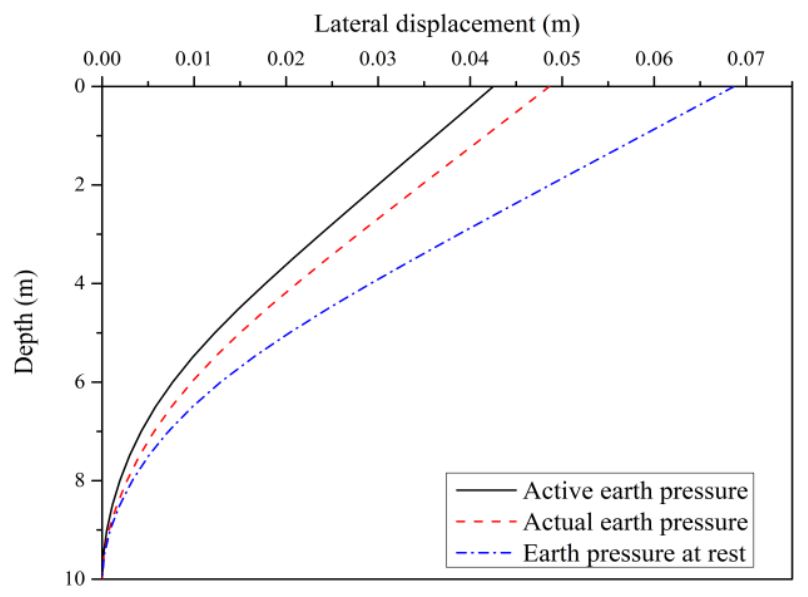

(b) The lateral displacement along the sheet pile under different earth pressure

Fig. 13 Comparison of the influence from different consideration of the earth pressure

behind the sheet pile

It can be found that the maximum bending moment along the steel sheet pile has a clear difference from the rest and active lateral pressure to the actual lateral pressure in Fig. 13. The comparison values are $31.4 \%$ and $9.8 \%$, which mean overestimate and underestimate. Meanwhile, the relative errors of the lateral displacement at the pile top are $12.5 \%$ and $41.3 \%$. It can also be seen that the curves of the bending moment on the upper pile under the active and actual earth pressure are similar because the earth pressure is nearly fully mobilized into active. Regarding the lower pile, however, the difference is dramatically increased. Hence the developed pile element incorporated the 
actual lateral pressure distribution can effectively capture the realistic bearing capacity.

\section{Conclusions}

Steel sheet piles, as a common supporting structure in the excavation projects, are often used in urban areas. The second-order effect and nonlinear SSI can highly influence the failure behaviour of the steel sheet pile. However, they cannot be accurately and efficiently reflected in the design. In this paper, a developed pile element is proposed to consider the realistic nonlinear SSI and second-order effect. Finally, three examples are selected to verify the accuracy and efficiency of the pile element. It can be found the nonlinear bucking can be accurately captured and compared with the analytical and semi-analytical methods. The pile element is much more efficient than the discrete spring element with increasing more than five times. With the consideration of the actual lateral pressure, the proposed element is strong in practical engineering.

\section{Acknowledgements}

The work described in this paper was partially supported by a grant from the Research Grants Council of the Hong Kong Special Administrative Regain, China (Project No. UGC/FDS13/E06/18). The third author would like to acknowledge Sun- Yat- Sen University for providing the "2019 Laboratory Open Fund Project of Sun Yat-sen University" (201902146), as well as the "Innovation Training Program for College Students" from School of Civil Engieering, Sun- Yat- Sen University. The last author wants to thank the support by the National Natural Science Foundation of China (No. 52008410).

\section{References}

[1] Denisov G. V., Lalin, V. V. and Abramov D. S., "Preservation of Lock Joints in Steel Sheet Piling During Vibratory Driving.", Soil Mechanics and Foundation Engineering, 51(1), 29-35, 2014

[2] Lee S. H., Kim B. I. and Han J. T., "Prediction of penetration rate of sheet pile installed in sand by vibratory pile driver.", KSCE J. Civ. Eng., 16(3), 316-324, 2012.

[3] Yan Q. Z., Rao J. and Xie Z. Q., "Research and Use of the Steel Sheet Pile Supporting Structure in the Yellow River Delta.", Advanced Materials Research, 243-249, 2684-2689, 2011.

[4] Du Z. L., Liu Y. P. and Chan S. L., "A second-order flexibility-based beam-column element with member imperfection.", Engineering Structures, 143, 410-426, 2017.

[5] Yang C., Yu Z. X., Sun Y. P., Zhao L. and Zhao H., "Axial residual capacity of circular concrete-filled steel tube stub columns considering local buckling.", Advanced Steel Construction, 14(3), 496-513, 2018

[6] Sobala D., and Jarosław R., "Steel sheet piles-applications and elementary design issues.", IOP Conference Series-Materials Science and Engineering, 245, 1-10, 2017

[7] Huo T., Tong L. and Zhang Y., "Dynamic response analysis of wind turbine tubular towers under long-period ground motions with the consideration of soil-structure interaction.", Advanced Steel Construction, 14(2), 227-250, 2018.

[8] Tapia-Hernandez E., De Jesus-Martinez Y. and Fernandez Sola L., "Dynamic soil-structure interaction of ductile steel frames in soft soils.", Advanced Steel Construction, 13(4), 361-377, 2017.

[9] Chen Z., Yang J. and Liu Z., "Experimental and numerical investigation on upheaval buckling of free-span submarine pipeline.", Advanced Steel Construction, 15(4): p. 323-328,
2019

[10] Fang Y. S., Chen T. J. and Wu B. F., "Passive earth pressures with various wall movements.", Journal of Geotechnical Engineering, 120(8), 1307-1323, 1994.

[11] Fang Y. S., Ho Y. C. and Chen T. J., "Passive earth pressure with critical state concept.", Journal of Geotechnical and Geoenvironmental Engineering, 128(8), 651-659, 2002.

[12] Lambe, T. W., and Whitman, R. V., Soil mechanics, John Wiley \& Sons, 1991.

[13] Rowe P., and Peaker K. J. G., "Passive earth pressure measurements." Geotechnique, 1965, 15(1): $57-78$.

[14] Han S, Gong J and Zhang Y. "Earth pressure of layered soil on retaining structures", Soil Dynamics and Earthquake Engineering, 83: 33-52, 2016.

[15] Sherif M. A., Fang Y. S. and Sherif R. I., "KA and K o Behind Rotating and Non-Yielding Walls", Journal of Geotechnical Engineering, 110(1): 41-56, 1984

[16] Fang Y. S. and Ishibashi I., "Static earth pressures with various wall movements", Journal of Geotechnical Engineering, 112(3): 317-333, 1986.

[17] Duncan J. M. and Mokwa R. L., "Passive earth pressures: theories and tests", Journal of Geotechnical and Geoenvironmental Engineering, 127(3): 248-257, 2001.

[18] Recommended practice for planning, designing and constructing fixed offshore platforms-Working stress design, American Petroleum Institute, Washington DC, USA, 2000.

[19] Phanikanth V. S., Choudhury D. and Reddy G. R., "Response of single pile under lateral loads in cohesionless soils", Electronic Journal of Geotechnical Engineering, 15(10), 813-830, 2010.

[20] Lee F., Hong S., Gu Q. and Zhao P., "Application of large three-dimensional finite-element analyses to practical problems.", International Journal of Geomechanics, 11(6), 529-539, 2011 .

[21] Wang S. T., L. Vasquez and X. Daqing, "Application of Soil-Structure Interaction (SSI) in The Analysis of Flexible Retaining Walls.", International Conference on Geotechnical \& Earthquake Engineering 2013, 567-577, 2013.

[22] Technical specification for retaining and protection of building foundation excavations, Ministry of Housing and Urban-Rural Development, PRC, 2012.

[23] Design of plated structures: Eurocode 3: Design of steel structures, part 1-5: Design of plated structures., British Standards Institution, London, UK, 2012.

[24] Liu S. W., Wan J. H., Zhou C. Y., Liu Z. and Yang X., "Efficient Beam-Column Finite-Element Method for Stability Design of Slender Single Pile in Soft Ground Mediums.", International Journal of Geomechanics, 20(1), 2020.

[25] Li X., Wan J., Liu S. and Zhang L., "Numerical formulation and implementation of Euler-Bernoulli pile elements considering soil-structure-interaction responses.", International Journal for Numerical and Analytical Methods in Geomechanics, 44(14), 1903-1925, 2020.

[26] Timoshenko, S. P. and Gere, J. M., General theory of elastic stability, Courier Corporation, 1973.

[27] Lee K. S. and Han S. E., "Semi-rigid elasto-plastic post buckling analysis of a space frame with finite rotation.", Advanced Steel Construction, 7(3), 274-301, 2011.

[28] Tang Y. Q., Liu Y. P. and Chan S. L., "A co-rotational framework for quadrilateral shell elements based on the pure deformational method.", Advanced Steel Construction, 14(1), 90-114, 2018.

[29] Iu C. K. and Bradford M. A., "Higher-order non-linear analysis of steel structures, part i: elastic second-order formulation.", Advanced Steel Construction, 8(2), 168-182, 2012.

[30] Huang Z. F., and Tan K. H., "FE simulation of space steel frames in fire with warping effect.", Advanced Steel Construction, 3(3), 16, 2007.

[31] Liu S. W., Liu Y. P. and Chan S. L., "Advanced analysis of hybrid steel and concrete frames Part 2: Refined plastic hinge and advanced analysis.", Journal of Constructional Steel Research, 70, 337-349. 2012

[32] Liu S. W., Liu Y. P. and Chan S. L., "Direct analysis by an arbitrarily-located-plastic-hing element - Part 1: Planar analysis.", Journal of Constructional Steel Research, 103, 303-315, 2014.

[33] Liu S. W., Bai R., Chan S. L. and Liu Y. P., "Second-Order Direct Analysis of Domelike Structures Consisting of Tapered Members with I-Sections.", Journal of Structural Engineering, 142(5), 2016.

[34] Vincent van D., "Global buckling mechanism of sheet piles: The influence of soil to the global buckling behaviour of sheet piles.", Delft University of Technology, 2020.

[35] Ni P., Mangalathu S., Song L., Mei G. and Zhao Y., "Displacement-Dependent Lateral Earth Pressure Models.", Journal of Engineering Mechanics, 144(6), 2018. 